\title{
The end of academic standards? A lament on the erosion of scholarly values in the post-truth world
}

Keith S Taber

[No abstract - as an editorial this article does not have an abstract]

I have recently been in correspondence with the staff of the Journal of Chemistry: Education Research and Practice, something which has brought home to me the extent to which academic standards and scholarly values are under threat. I should point out, just in case it is not obvious, that the Journal of Chemistry: Education Research and Practice has absolutely nothing to do with this journal, Chemistry Education Research and Practice. This other journal is just one of countless new journals and conferences appearing in a marketplace selling the opportunity for academics to present their work, or allowing scholars to acquire credentials by being named as members of conference organising committees, editorial boards, or even editors, without requiring any conference organising, strategic oversight of journal policy, or editorial work. The work of these journals and conference series seems to be undertaken with no knowledge of the relevant academic field. Indeed, any direct engagement by scholars having actual expertise would probably amount to a distraction from the core commercial activity of generating revenue streams by selling academic credit. Having a purely technical role, the administrators are often able to work across a suite of journals or conferences on a diverse range of foci without being hampered by the inconvenience of needing to know anything about the disciplinary fields within their remit.

\section{Values and the academic life}

As a child I aspired to be a scientist and work in a university, although I cannot at that time have had much idea of exactly what this would involve beyond it seeming a noble calling that would allow me to work in science. Later when I trained as a teacher and entered the education profession that role appealed at several levels. Working in a school (as I did originally) meant I was working with my science, and attempting to explain chemistry and physics to young people, and enthuse them about science. Alongside this, though, was a broader notion of public service, of teaching being useful to society, of education as about helping young people grow intellectually and reach their potential, and - in 
particular - of the centrality of values to educational work. Every teacher has a level of pastoral responsibility towards their students (which may sometimes include offering moral guidance) whatever subject they are employed to teach, and I still think that teaching at all levels is as much about being a role model being seen to be a virtuous person - as teaching a curriculum subject.

I do now work in a University, albeit in an education faculty rather than within natural sciences. I still see values as central to my work, and luckily work in a context where this view is widely shared. Yet I have long recognised tensions in the role.A key example relates to the competitive nature of academia. Students I have supervised need references for jobs and other opportunities. Students applying to work under my supervision often require supporting statements for various scholarship competitions. I obviously want to do my best by these students, and offer a strong case: but only providing I am being totally honest. I can only argue that a proposal for funding is exceptional if I consider that is the case. I can only say a student is the best I have worked with for years, if I feel this is so. Yet it seems that evaluating proposals as (only) very good, or reporting that a student is (only) very strong, is seldom likely to be enough in a very competitive context. I do the best I can to offer a strong case without going outside my perception of the actual situation - and believe that is fair to both 'my' students and everyone else.

This assumes that 'everyone else' takes the same stand, and is also being as honest and even-handed as they can be. As this is academia, I had always thought - or at least hoped - it is reasonable to assume that should generally be the case. I am beginning to wonder if I am just naive. A student from another institution recently wrote to me, and as part of the message stated that "you are the leading researcher in science education in the world". I clearly do not think that is so, yet would like to think that if a student wrote that, then that student genuinely (even if mistakenly) thought so. I would much rather a request for help came from someone who was honest, than someone who thought false flattery was needed.

In the past few years, however, l've noticed that the world of academia has been increasingly infected by norms which to my mind have no place here. This goes beyond the imperative to 'sell ourselves' which grates with the traditional British approach of employing understatement and leaving it for others to make up their own minds. Probably we have moved beyond the time when overseas students in England needed a phrase book to interpret that when their work was 'rather good' the tutor was actually extremely impressed, and that when it 'could do with some tweaking' it probably needed completely rewriting as it was substandard. Yet going around telling people that I think I am 
a leading academic in a prestigious department in world-leading university still seems quite (i.e., very) inappropriate. Even if I were egocentric enough to immodestly think so, surely what matters are the evaluations that others might make of my actual work - evaluations made without my seeking to influence their opinions through self-aggrandisement.

Even if too much self-publicity goes against the grain, I can perhaps consider that a matter of style, rather than a portent of the end of times. Recently, however, l've been increasingly concerned, irritated, frustrated, and sometimes even upset, by how the world of academic scholarship has increasingly been infiltrated by those with no concern for honesty and truth and who embrace a culture of exaggeration, flattery, misdirection, and downright lying.

\section{Too much of a good thing}

Like most readers of this journal I suffer from the unseen consequences of the gift of free email. Unlike when sending a letter, anyone with an internet service can write to anyone else who has email, or indeed in principle to everyone else who has email, for no substantial cost. Once you have the computer, an email application, and a link to a service provider, you can readily email anyone whose email address you can find. Academics commonly have their contact details on their university webpages, and reported on their publications. Harvesting email addresses is not difficult, and of course there is a market in lists of such addresses.

In the days of pen and ink, writing to ten people was ten times as much time, effort, resource, and cost, as writing to one. The arrival of photocopying and home printers meant you could write one letter and make copies for all your friends, but this still needed multiples of paper, envelopes, and stamps. However, once an email distribution list is set up on an email application, it is as easy to send an email to ten people as one. Indeed to a hundred people, a thousand people, ten thousand people ... as one.

When posting out paper-based calls for conference papers or journals, it used to be important to target people likely to be potentially able to contribute - or the investment of resources involved was wastefully inefficient. But if you email such a call to many thousands of people then perhaps all that matters is you 'hit' enough people who might be interested: $1 \%$ ? $0.1 \%$ ? $0.01 \%$ ? If you send the email to enough people then an acceptable hit rate can be very small indeed. 
Even this seems inconsiderate rather than dishonest. No one likes getting a plethora of unsolicited emails about things of no interest that then have to be sorted from useful mail. But as there is no substantial cost to sending indiscriminate emails, many organisations do just that. We might think there could be a reputational cost to the organisation indiscriminately emailing, but perhaps not. If you get an email that does not seem relevant, you think badly of an organisation you probably know nothing about and which you were never going to engage with anyway - no harm done, as far as they are concerned. It is a minor irritation to you (which can be multiplied by the thousands of such emails you get; or the thousands of other recipients who also receive and have no interest in that message). If you are one of the few for whom the message actually seems relevant, and so you might potentially engage with the sender, then you may not be aware that for every recipient like you there are countless others who are hitting the delete key and are perplexed about why they have been invited to that particular conference or asked to contribute to that specific journal.

\section{The rise of general academic services}

Somewhat mitigating this 'scatter-gun' approach to blanket marketing of academic 'opportunities' is the shift away from specialisation: from the organisation that has a particular interest in some field or topic, and arranges meetings and publications for a targeted scholarly community with which it develops a relationship. It is quite normal now to receive invitations to talk, or to submit writing, from a suite of conferences or journals that cover diverse fields. I was once an 'invited speaker' at any one of a number of conferences on 'Energy, environment, entrepreneurship, innovation'; 'Social science, social economy and digital convergence'; 'Manufacturing, commerce, tourism and services'; or one of a number of law conferences.

The message here seems to be that the organisers are too lazy to make any effort to find out what you work on, but surely you consider yourself an expert in one of these myriad topics? They behave like dodgy traders approaching punters in a busy marketplace: Can I interest you in a watch? No, then what about a new computer? Or a jacket? Some golf clubs perhaps? Surely we must have something that will interest you: if not our social science conference, then what about this one on engineering, or the one about the humanities?

It only takes a few seconds to scan and delete an email. But it does take focus and concentration away from other tasks. If someone only gets about 25 
nuisance emails in a week (and which of us is that lucky?) then over a year that is enough email that need to be considered and deleted to take up an hour of valuable time. Spam and Junk filters can do some initial sorting, but inevitably make both type I and type II errors - missing some nuisance emails and misfiling some genuine correspondence. So we still have to go through and check.

Nuisance emails used to be about such matters as openings in unlikely jobs; promises of undeserved money, goods at slashed prices, and miraculous pills; news of friends allegedly stranded abroad urgently needing funds sent to them; and offers of love, companionship (sometimes of a very adult nature), or eternal salvation. Now I seem to get just as many about scholarly journals and academic or professional conferences and the like. With increasing numbers of academics needing to populate their curricula vitae to demonstrate suitability for employment, tenure, or promotion, there has been an explosion of new journals and conferences offering dissemination of academic work - at a cost. A few of these are organised by groups of academics sensing a genuine need for a new forum: but most seem motivated by the profit motive and initiated purely out of commercial interests.

There is of course nothing wrong with someone establishing a new journal or a new conference: and just because something is new does not mean it is not well meant or that it might not aspire to high quality. There is also no 'in principle' reason why commercial organisations cannot offer quality in these areas - after all, some of the most respected academic publishers are commercial businesses. As respected organisations, those publishers tend to be honest in their marketing. Many (not all, but from my own experience I suspect most) of the new wave of academic publishers and conference organisers lack such scruples, and are perfectly happy using advertising tricks and even downright lies to get academics to engage and part with money.

\section{Developing evil clones}

One approach is getting people to pay for services is to clone an existing successful enterprise. The trick here is to use a name which might be confused with an established and prestigious scholarly activity. As I worked on this editorial I received an email offering proof reading, editing and translation services from an organisation calling itself Spingar Editing Org., or alternatively Springedit Proofreading Inc., suspiciously similar to the names of the wellknown publisher for the healthcare professions Springer Publishing, and the even better known general academic publisher Springer Science+Business 
Media. Perhaps that is just a coincidence, but l've seen quite a few such coincidences recently.

In October a colleague and former Board member of this journal was invited by the founding editor of the Journal of Chemistry: Education Research and Practice to join that new journal's editorial board. The journal name seemed very close to Chemistry Education Research and Practice, and I wrote to suggest they should avoid confusion by changing the name before they actually started publishing. The editor replied to acknowledge that "we can understand your doubts" - and asked me to let them know if I wanted to be on the Board. I wrote back to suggest again that they should modify the name to "allow the academic community to see your new journal as a genuine attempt to add to the range of scholarly publications in the field, rather than simply employing a cheap trick to mislead authors".

A month later I heard from an editorial manager of the new journal to request I might "write a Research Article, Review Articles, Case Reports, Short Review, and [sic] Short Commentary based on your research interest" which could be published for free. I would have to produce my manuscript within two weeks to meet the deadline for this introductory offer. I wrote back pointing out that the statement on their website that the "Journal of Chemistry: Education Research and Practice is a leading International Journal for the publication of high quality articles" had to be seen as a deliberately misleading claim given that the journal had not yet published a single article. This claim was not phrased as an aspiration, but as a matter of fact, and as such it was a clear falsehood.

Having looked at their website, it becomes clear that the journal name is not only a near clone of an existing journal, but inappropriate in its own terms. The journal invites papers in the areas of analytical and inorganic chemistry; applied and materials chemistry; biochemistry; biological, medicinal, environmental chemistry; chemical physics; organic and biological chemistry; materials science; nuclear chemistry; petroleum and petrochemicals; pharmacognosy and phytochemistry; polymer chemistry; spectroscopy; stereochemistry and clinical chemistry; theoretical and physical chemistry - but not, it seems, chemistry education. Any suspicion that the name was accidentally chosen seems less viable given that it is not even a suitably descriptive name for the planned journal.What does seem likely is that the journal name has been selected, and the journal set up, prior to the involvement of anyone who knows much about chemistry education, or indeed chemistry. 
This is not an isolated case. A few months ago I received an 'honorable speaker invitation' to present at the 8th edition of the International Conference on Chemical Education. The International Conference on Chemical Education (ICCE) is a well established conference series, under the auspices of IUPAC (the International Union for Pure and Applied Chemistry). I recall going to the I I th ICCE Conference many years ago - so how come they are only now holding the 8th?

The 24th conference was held in Malaysia in 2016.Well, this ICCE inviting me to speak was not the same ICCE but a clone - not organised by the established learned society IUPAC, but by an 'events company' called EuroSciCon Ltd. Again one is left choosing between assuming that the organisers selected a name without realising it was already 'taken' (which would suggest no one was involved from the field concerned, and no one thought to do a quick search on the world wide web) or this was a deliberate choice intended to confuse potential delegates. Either way, this does not reflect the values expected of the scholarly community.

\section{They flatter to deceive}

This is certainly not an issue which is particular to chemistry education. In other fields I might not be as well placed to recognise tricks such as cloning existing names, but I certainly recognise how false flattery is being used to engage academics in various enterprises. If I receive an invitation from someone claiming that I am accomplished in chemistry education or science education I might well be immodest enough to take this at face value. When I am praised for my work in various other fields I have to assume the praise is no more than a cheap trick to get me to think I am especially valued - in the hope I will sign up to give a talk, or write something, or agree to join a board, or whatever.

I have previously blogged on that particular issue commenting on how I have been described as, inter alia, eminent in biology; an expert in computer science; an eminent contributor to medical science; prominent in immunodiagnostics; a significant contributor to psychotherapy; and so forth (http:// people.ds.cam.ac.uk/kst24/KeithSTaber/Science-Education-Research/ScienceEducation-Research.html) Even in chemistry and physics, where I do know a little, I have not, despite being told otherwise, made immense contributions to atomic and nuclear physics, nor an eminent contribution to computational chemistry. 
One wonders: is the logic again that it does not matter if you compliment people out of field who will realise it is a scam, as long as you reach enough people who might think you really do admire their scholarly work? Even within a field, most people would surely know already whether they are eminent, so is part of the trick to offer evidence that those accepting the invitation can use to later claim that they have been invited to speak or write or join a board based on their (non-existent) international reputation as a leader in the field? These academics pay good money to be involved in a low status (but impressively titled) journal or conference, and this allows them to claim invited publications, keynote speaker status, etc., on their resumé. This is not likely to be a good investment, as those who make recommendations on appointment, tenure, and promotion, decisions surely only take into account those journals and conferences they know to be important in a field. I know that is how I think when asked to make such an evaluation.

\section{A fantastic fit}

Sometimes the ploy used is to suggest that one's published work is perfectly fitted to the task in hand - even if that may not seem so obviously the case. The organisers of the 4th Annual World Congress of Smart Materials felt that one of my published studies is a perfect fit for the meeting. They had a slot left in the session on 'Materials for Solar Energy and Solar Microgrid' where they had decided that I could give a 'fantastic speech'. They wanted me to talk on the topic of one of my publications: 'Upper secondary students' understanding of the basic physical interactions in analogous atomic and solar systems' (Taber, 20I3). The only rationale that occurs to me is the use of the word 'solar' in the title, leading me to wonder if they had considered inviting Julie Andrews to reprise her seminal presentation of 'Do-Re-Mi[-Fa-Sol-La-Ti]' from the influential Rodgers \& Hammerstein (1959) publication.

I replied to point out that I was "struggling to see how it would be of interest to experts in materials science. Do they really want to hear about how school students may transfer ideas incorrectly between their understanding of the forces acting in the solar system, and their developing thinking about basic models of atomic structure?" This elicited a response that "we hope you could make a keynote Speech under Session 705: Materials for Solar Energy and Solar Microgrids". I replied that "I remain a little perturbed however, that specialists in smart materials who I appreciate might want to hear the latest developments and ideas in the topic of Materials for Solar Energy and Solar Microgrids are surely unlikely to find a talk considering conceptual difficulties 
that impact secondary level pedagogy of particular interest", which led to a response that they hoped that I "could make the Keynote Speech under Session 705: Materials for Solar Energy and Solar Microgrids" although they "couldn't cover the expense for our invited speakers".

Being an invited speaker, asked to give a keynote or a plenary talk, used to be a meaningful honour. However, a recent circular inviting me to a suite of conferences on Energy, Environment and Earth Sciences;Architecture and Urban Planning; and Civil Engineering; included a web-link button to apply to "Become Keynote Speakers" - I assume in the new post-truth academia a keynote speaker is now someone who pays the organisers a premium rate to present at a conference. Perhaps by this time next year I will have received the first email of many inviting me to open the bidding in some commercial organisation or other's annual round of auctions for scholarly awards, prizes, and medals, across a spectrum of scholarly fields.

There is a saying that 'if you can't beat them, join them'. So in honour of my pension fund I announce that I am initiating the first annual Keith S. Taber award in Chemistry Education. In this internationally recognised scheme (seen as second only to the Nobel prizes in my house) it costs only a 50 Euros handling fee to nominate someone for an award, and self-nominations are more than welcome. Applications require a c.v. (no more than 2 sides of A4) with a citation summarising achievements in the field of no more than 100 words, along with a sealed bid of what you will pay for an award. For premiere applicants, for only an extra 50 Euros, I will write your citation for you if you win one of the bronze, silver, or gold, awards that will be earned by the three highest bids I have received by the end of June 2018. If that competition is well received (and my pension fund suitably enhanced), then I might develop 'the concept' further to inaugurate Keith S. Taber awards in other fields: starting in 2019 with Immunodiagnostics and Psychotherapy.

\section{Lies, 'dammed lies', and scholarly solicitations}

Exaggeration and flattery sometimes become outright lies. Earlier on the day I drafted this editorial article I received an invitation to contribute manuscripts to a journal on rheumatology and orthopaedic medicine. This time I had just over two weeks to complete and submit an article to get a discount on the publication fee.A normal person who does not do any work in rheumatology and orthopaedic medicine, especially one not accustomed to paying publication fees in any case, would simply junk the email. However, the invitation included a claim that irked me. 
The email came from a professor, although it had been sent on his behalf by his editorial assistant. It included the explanation that I was being contacted because they had read my publications and selected me as a suitable author for their journal (yes, the one on rheumatology and orthopaedic medicine). I was told "we have gone through your papers and find it is a wonderful resource for upcoming works". So either the people running this journal can see a strong connection between my work on student conceptions, or teaching science to gifted learners, or whatever, and autoimmune disease - a connection that is escaping me - or this email contained a clear lie. I suspected that they had not actually accessed and read my work and were simply lying to me.

I decided to do a quick internet search: was this professor real? Did he really edit a journal? Did he really do research in this area? After all, a previous attempt to identify the academic affiliation of a 'Prof. Dr. Kostas Ciotopoulos' who had "invited" me to be an "invited speaker" at one of a curiously unspecified range of conferences had failed to find any reference to such an academic or indeed to any scholarly publications by someone with that name even though speaking at his conferences would seemingly allow me to publish my presentation in one of a wide range of journals by established publishers such as Springer Verlag.

In this case, however, it soon became clear that the editor was a serious academic with a senior position in the field of the journal and a strong record of research and publication. I also found his academic email address (not the journal email that his invitation came from) and wrote to him to ask if he or his staff had really read my papers. He of course had not heard of me so was sadly not a fan of my scholarly work, and nor had he seen the wording of the email sent out on his behalf. It seems he was not aware what was being done by the publisher using his name.

\section{Guilty by association}

I doubt this is that unusual. Earlier in the week I was invited to speak at a conference in Japan on degenerative diseases - yet another topic I clearly know nothing of special worth about. The theme was 'Novel Research and Diagnostic Mechanism for Improving Alzheimer's and Parkinson's Disease'. Presumably it was not so much these distressing diseases they actually wanted to improve, rather the situation of disease sufferers, but perhaps precise phrasing is not seen as important in this area of research. 
It seemed obvious that although the conference organisers wanted my "gracious presence as a Speaker", and again the email was addressed to me by name, this was not really a request to be an invited speaker, but simply a circular for a conference. To demonstrate the academic credentials of the conference, a list of eight academics from the organising committee, with their institutional affiliations, was included at the foot of the invitation. I was able to search out email addresses for these committee members, and so include them in my response asking why they wanted me as a speaker.At the time of writing this editorial, l'd heard from five of these academics. One had agreed to be on the committee, but had not been asked to actually offer any input at this point. Another had joined the committee on the understanding that this was an honorary position that did not involve actually doing any organising. The other three had no idea their names were being listed in this way, had not agreed to be on any such committee, and had been unaware that their names, photographs, and biographies appeared on a conference webpage detailing the organising committee. So this is not only a matter of lying to me and other people sent similar invitations, but also a kind of identity theft of at least three of the academics concerned.

One of the professors who got back to me told me his only connection with the conference was having received a similar invitation to speak, which he declined after being told that such an invitation did not entail reimbursement of expenses incurred attending the conference. That lack of financial reimbursement did not surprise me. I am still waiting to hear back from the organisers of a conference on 'Regenerative Medicine \& Stem Cell' (and yes, the title did stop at that point) to find if they will pay my expenses if I accept their invitation to give a presentation in the conference session on eye diseases. Why me? Perhaps because I had contributed to a book that referred to 'theoretical lenses' (Alsop, Bencze, \& Pedretti, 2005) in the title? Or because my work often refers to pupils? Or perhaps I am genuinely considered a scholar of great vision? Well, perhaps. Your guess is as good as mine.

\section{Is it too late to stop the rot?}

Something is rotten in the state of academia. It is very hard to see how graduate students and new academics are meant to cope with balancing the pressure to build up their c.v., whilst avoiding being taken advantage of by all the charlatans, cheats, liars, and other con artists, that will fill up their in-boxes with seemingly prestigious invitations to speak (at a cost), publish (at a cost), or to join various boards and committees which will have no strategic or executive control over what commercial administrators will then do in their 
names. I am not sure how to stop the rot, but unless the scholarly community finds a way to express its values and maintain clear standards academia will become clogged up with academically worthless (if commercially profitable) conferences and journals that offer little more than vanity publishing.

Perhaps at the very least the community should find a very public way of naming and shaming those organisations that ignore academic standards and disregard the values of honesty and openness that are essential to good scholarship. But if you feel that is wildly optimistic, then perhaps instead consider bidding for one of the prestigious and influential 2018 Keith S. Taber prizes for Scholarly values and academic integrity. If you are too modest (or impoverished) to nominate yourself, then perhaps a parent or spouse would considering sponsoring a bid on your behalf as a New Year present?

\section{References}

Alsop, S., Bencze, L., \& Pedretti, E. (2005). Analysing exemplary science teaching: theoretical lenses and a spectrum of possibilities for practice. Buckingham: Open University Press.

Rodgers, R., \& Hammerstein, O. (1959). The Sound of Music.

Taber, K. S. (2013). Upper Secondary Students' Understanding of the Basic Physical Interactions in Analogous Atomic and Solar Systems. Research in Science Education, 43(4), I377- I406. doi: 10.1007/ sl| |65-0|2-93 |2-3

Keith S.Taber University of Cambridge faculty of Education kst24@cam.ac.uk 